\title{
Utilitas: la dimensión práctica de la formación universitaria
}

\section{Augusto Hortal Alonso, SJ'}

Palabras clave: dimensión práctica, ejercicio profesional, utilitarismo.

Key words: practical dimension, professional performance, utility.

\begin{abstract}
Servir al mundo con descuido y pereza poco importa; mas servir a Dios con negligencia, es cosa que no se puede sufrir. SAN IGNACIO DE LOYOLA

No está permitido ser torpe cuando el fin es bueno. Si la habilidad no es por sí misma una virtud, es ciertamente condición suya, y la excesiva ingenuidad no está lejos de ser un vicio. PierRe Aubenque

Quien no sabe encontrar el camino que conduce a su ideal lleva una vida más frívola y descarada que el hombre sin ideal. FrIEDRICH NIETZSCHE
\end{abstract}

\section{La "utilitas" entre la teoría y el utilitarismo}

De las cuatro dimensiones que el documento marco de UNIJES propone para definir la identidad y misión de nuestros centros universitarios a mí me toca presentar el tema más fácil y por eso mismo el más difícil. El más fácil porque es

${ }^{1}$ Augusto Hortal Alonso es jesuita, profesor, recientemente jubilado, de Ética y Filosofía Política en la Facultad de Ciencias Humanas y Sociales de la Universidad Pontificia Comillas. Dirige la Colección UNIJES de Ética de las profesiones que se publica en la Editorial Desclée de Brouwer. 
el menos cuestionado y en cierto modo el que más realizado está y más se nos suele reconocer como característica de nuestros centros. De ellos salen, se dice, profesionales competentes, capaces de responder con éxito a las expectativas de una vida profesional exigente. El tema más difícil, porque esa realización está profundamente distorsionada en la medida en que "amenaza con anegar todo lo demás": "Concentrarse exclusivamente en los elementos pragmáticos de la educación, sólo en el progreso económico, simplemente en el progreso científico y tecnológico, solamente en intereses económicos, puede fácilmente reducir el fin práctico de una universidad a una estrecha perspectiva que convierte las otras tres metas de la vida universitaria en meras abstracciones." 2

Por eso, conviene empezar aclarando el concepto de utilitas, una de las cuatro características que el Consejo de UNIJES ha querido destacar como elemento identificador de la formación que se proponen ofrecer los centros universitarios de la Compañía de Jesús.

Cuando en la segunda mitad del siglo XVI el P. Ledesma se estaba planteando las razones por las que la Compañía de Jesús debería mantener instituciones educativas, la primera razón que da es "porque proveen a la gente con muchas ventajas para la vida práctica". Eso es lo que hoy se traduce diciendo que la educación jesuítica es eminentemente práctica, concentrada en proveer a los estudiantes con el conocimiento y las habilidades para sobresalir en cualquier campo que elijan. ${ }^{3}$

No es un capricho esta designación que hunde sus raíces en la tradición de la Ratio Studiorum y que el P. Kolvenbach ha rescatado y puesto de nuevo en circulación en algunos de los importantes documentos y discursos tenidos en las distintas universidades jesuíticas. El último de ellos, dirigido al Consejo Directivo de la Universidad de Georgetown, contiene este párrafo:

Más bien, una universidad jesuita será eminentemente práctica cuando siga insistiendo en una formación integral y en un enfoque holístico de la educación, que ustedes están haciendo tan bien. Tiene Utilitas porque responde a la obvia necesidad de la sociedad humana de considerar el progreso técnico y todas las especialidades científicas, a la luz de las más profundas implicaciones humanas, éticas y sociales, de modo que la ciencia y la técnica sirvan a la humanidad y no lleven a su destrucción. ${ }^{4}$

\footnotetext{
2 Peter-Hans Kolvenbach (2008), Discursos universitarios, Madrid, UNIJES, núm. 8, p. 260.

${ }^{3}$ Ibid., núm. 5, p. 259

${ }^{4}$ lbid., núm. 8, p. 260.
} 
Que la dimensión práctica sea designada con la palabra latina utilitas hace pensar en el utilitarismo. Puede servir de antídoto recurrir a la forma de entender "útil" y "utilidad" en los siglos anteriores. Para Santo Tomás el bien humano, cualquier bien, se presenta bajo tres posibles formas: lo honesto (bonum honestum), lo agradable (bonum gratum) y lo útil (bonum utile). Mientras que los dos primeros son bienes terminales o bienes en sí (lo que no significa que sean bienes absolutos que no puedan a su vez estar relacionados e integrados en bienes más amplios o superiores) el bonum utile tiene su razón de ser y su bondad en estar al servicio de otros fines o bienes terminales.

"Utilidad" no figura entre las entradas del Tesoro de la Lengua Castellana o Española de CovARRUBIAS. En cambio el Diccionario de Autoridades (original de 1726, reeditado en facsímil por Gredos, Madrid, 1963) entiende utilidad como provecho, conveniencia, interés o fruto, que se saca de alguna cosa en lo psysico, ú moral. Y unas líneas más abajo con caracteres más pequeños añade: Se toma también por la capacidad o aptitud de las cosas, para servir ú aprovechar.

No es el saber por el saber lo que busca Ignacio cuando a sus 34 años empieza a estudiar, sino se propone estudiar para ayudar. El "ayudar" ese verbo tan radicalmente ignaciano, y el hacerlo con provecho, de eso trata la utilitas. En su Autobiografía san Ignacio nos cuenta cómo tras su conversión en Loyola y sus Ejercicios en Manresa peregrinó a Jerusalén con la idea de quedarse allí para siempre. Todo su afán era estar cerca de los lugares en que había vivido el Señor Jesús, tratando de palpar con los cinco sentidos las huellas de su paso por este mundo. Como no se lo permitieron, volvió a Barcelona y empezó a darle vueltas a la idea de estudiar para poder mejor ayudar a otros. Así es como a sus 34 años se sentó en un pupitre y empezó a aprender los rudimentos del latín. Diferentes vicisitudes le fueron llevando de universidad en universidad: primero a la de Alcalá, luego a la de Salamanca y por fin a la Universidad de París. Allí consiguió reunir un primer grupo de universitarios que se proponían entregarse a Dios y poner sus conocimientos al servicio de un ministerio sacerdotal itinerante. Luego en las Constituciones, al enumerar algunos criterios para seleccionar los ministerios a los que debían ser enviados los jesuitas, situaba en un lugar preferente a las universidades, porque en ellas se juntan personas que ayudadas podrán ser operarios para ayudar a otros. ${ }^{5}$

No sólo la educación jesuítica es práctica, la misma espiritualidad ignaciana supone, incluye, asume y anticipa la nueva manera de verse y vivirse la jerarquía entre

${ }^{5}$ Constituciones, $\mathrm{n}^{\circ} 622$ 
teoría y praxis, entre acción y contemplación. La centralidad de Dios no está en discusión. Pero ya no se considera que esa centralidad tenga que traducirse en la prioridad de la vida contemplativa sobre la activa. Los jesuitas y quienes con ellos comparten la espiritualidad ignaciana están llamados a ser "contemplativos en la acción", colaboradores de un Dios que siempre y en todo trabaja. Dios no está ocioso y el jesuita tampoco debe estarlo; hay mucho que hacer en esta historia de la salvación en que hemos sido embarcados. El que aprendamos a hacerlo bien -supuesta la pureza de intención- requiere que las cosas sean hechas con eficacia y con eficiencia. De eso se trata en la utilitas. Y eso es lo que afirma el primer lema que hemos puesto a estas líneas: Servir al mundo con descuido y pereza poco importa; mas servir a Dios con negligencia, es cosa que no se puede sufrir.

Después de haber contrapuesto la utilitas al mero saber teórico y contemplativo conviene también marcar distancias frente al pragmatismo y utilitarismo actual para evitar malentendidos. En nuestro quehacer universitario es fácil que nuestros alumnos salgan más competentes ("útiles") que vinculados a fines y valores honestos o incluso fruitivos. La fides, la humanitas y la iustititia deben insistir en esto, pero no recortando la dimensión práctica, sino haciendo que esté al servicio de las otras dimensiones. Esto es importante y volveremos sobre ello en la última parte de nuestra intervención. No está permitido ser torpe cuando el fin es bueno, segundo lema que hemos tomado de Pierre Aubenque, intérprete de Aristóteles.

El utilitarismo como escuela de moralidad está muy presente en la mentalidad actual; también impregna y configura muy íntimamente los planteamientos de la economía y de la psicología. Desde ahí se hace presente en la cultura actual y, por supuesto, también en la cultura universitaria. No es éste el momento de hacer disertaciones teóricas sobre el utilitarismo y las teorías éticas alternativas (kantianas y aristotélicas). Pero sí se hace necesario recalcar dos diferencias fundamentales entre el cálculo de utilidad de la moral ultilitarista y la propuesta de que la utilitas sea parte integrante de la formación que proponen e intentan promover los centros universitarios de la Compañía de Jesús.

Para el utilitarismo no hay acciones que sean buenas o malas en sí; el único criterio de moralidad se toma del cálculo de las consecuencias que dicha acción reporta para la mayor felicidad del mayor número de personas afectadas por dicha acción, entre las que el agente cuenta como uno más. Por felicidad se entiende todo tipo de placer o ausencia de dolor. Como las formas de disfrutar y sufrir son muchas y variadas, cabría decir que el utilitarismo propone como único criterio de moralidad aumentar las satisfacciones y disminuir las frustraciones de los deseos humanos. No entremos en mayores complejidades. 
La utilitas, según la veo, no tiene ni mucho menos la pretensión de ser ni el único ni el último criterio de moralidad. Esto es ya una diferencia importante. Según Santo Tomás lo que el bonum utile tiene de bonum lo recibe del fin al que sirve. Cuando se habla de utilidad o de sentido práctico hay que preguntar: ¿útil para qué? oo sólo para disfrutar, sino para vivir y ayudar a vivir con dignidad y en plenitud, para una mejor humanitas, una mayor iustitia, una mejor fides, es decir para mejor amar y servir en todo. Esta conexión de la utilitas con los fines ulteriores es importante; volveremos sobre ello en el último apartado de esta intervención.

\section{Enseñamos para formar profesionales competentes y...}

Vivimos en un mundo que no es posible, ni se entiende, sin el conocimiento científico, técnico y organizativo. La universidad es la principal institución en la que se obtienen, se amplían y se transmiten esos conocimientos; en ella se forman los cuadros profesionales y se elabora el conocimiento que ha ido mejorando las condiciones de vida, estructurando la convivencia, buscando las formas de gestión más eficiente. Investigar, ampliar los conocimientos metodológicamente controlables, se investiga investigando con arreglo a los métodos y usos de cada disciplina. Algo semejante hay que decir de la docencia. Las funciones universitarias tienen su propia lógica interna que hay que respetar escrupulosamente.

Es ya hoy un lugar común, pero sigue siendo importante decir y repetir que una universidad de la Compañía, para serlo de veras y plenamente, tiene que ser ante todo auténtica universidad. Sólo siéndolo puede además ser verdaderamente jesuítica. Poner unas instituciones universitarias al servicio de la misión de la Compañía no es, no debe ser, no suele ser, instrumentalizarlas, ni tampoco recortar su pleno sentido universitario. Al revés, para que las universidades de la Compañía puedan prestar un auténtico servicio a la fe, y contribuir a la promoción de la justicia, al diálogo intercultural e interreligioso, hay que empezar por "evitar toda instrumentalización simplista". ${ }^{6}$

En el pasado y en la actualidad ha habido y hay algunos buenos investigadores y buena investigación en los centros universitarios llevados por la Compañía. Cuanta más haya y mejor sea, mejor, sobre todo si se trata de temas relevantes para la vida de las personas, especialmente las más vulnerables y desfavorecidas. Sin embargo, por la misma orientación y por la forma de financiarse, las universidades de la

${ }^{6}$ Congregación General 34, Decreto 17, no. 7. 
Compañía destacan más por la docencia que por la investigación. No se trata sólo de que haya buenos, a veces muy buenos docentes; es que la cultura pedagógica y organizativa logra además un óptimo aprovechamiento de capacidades docentes ordinarias. Pero por encima y a través de las funciones universitarias en lo que destaca y busca destacar la tradición universitaria de la Compañía es en la formación de las personas: investigadores, docentes, profesionales competentes que contribuyan a crear un mundo más justo, más humano y por eso mismo más divino, que sean de veras "hombres y mujeres para los demás". ${ }^{7}$

Tal vez hubo un tiempo en el que la universidad se podía entender como templo del saber o torre de marfil donde se busca el saber por el saber. Ese tiempo, ciertamente, no es el nuestro. No sólo porque lo diga Bolonia. Al revés, Bolonia no ha hecho más que explicitar lo que venía siendo una evolución imparable: las universidades, sin dejar de ser lugares en los que se investiga, son, cada vez más, lugares en que se forman los profesionales cualificados que necesita la sociedad.

Dicen que en las facultades medievales de medicina se cultivaba un saber médico especulativo y experimental, descuidando casi del todo la formación clínica. De hecho no se necesitaba haber pasado por la universidad para ejercer la medicina. Durante muchos siglos, prácticamente hasta la edad moderna, los médicos eran propiamente curanderos, expertos artesanales en el arte de curar que basaban sus actuaciones en conocimientos acumulados generación tras generación y trasmitidos de padres a hijos o de maestros a aprendices. Aristóteles, hijo de médico e interesado por la medicina como refleja en sus muchos ejemplos tomados de esa práctica, decía que a los médicos les bastaba con saber que esta pócima o aquel emplasto curaba; en cambio, saber por qué curaban era algo que contribuía a la perfección intelectual de quien lo sabía pero no al arte médico propiamente tal. Por decirlo en nuestra terminología cuatridimensional el saber teórico contribuiría a la humanitas, pero no a la utilitas. Aristóteles concebía la práctica médica como el "arte" (techne) de conseguir curaciones (un fin práctico) y no un saber parcialmente fundamentado en la ciencia, que es como la entendemos hoy.

Esta situación ha cambiado radicalmente con el progresivo acercamiento de las profesiones a los conocimientos científicos que se investigan y se imparten en las universidades. La aplicación de los conocimientos científicos a la práctica

\footnotetext{
${ }^{7}$ Esta expresión que D.Bonhoeffer aplica a Jesucristo, es la que puso en circulación el P. Arrupe en su intervención en el Congreso Europeo de Antiguos Alumnos (Valencia, 1973). La expresión ha hecho fortuna y sirve para designar la meta formativa de nuestros centros educativos. Cf. C.G. 34, D. 3, $n^{\circ}$ 20.
} 
profesionalizada ha potenciado y enriquecido la vida profesional. A su vez las universidades han experimentado una profunda transformación cuantitativa y cualitativa. La proliferación de las carreras universitarias ha ido en paralelo con la progresiva profesionalización de las actividades. Si las carreras universitarias hace 50 ó 60 años eran poco más de 20, hoy superan las 100. Esa característica de la evolución social está en sintonía con una de las características de la formación que han pretendido ofrecer los centros universitarios de la Compañía de Jesús.

Lo que nos propone Bolonia y lo que me propongo presentar aquí es una forma de reflexionar sobre cómo contribuye lo que hacemos enseñando en el horizonte de esa formación para la práctica profesional que cada titulación ofrece. No enseñamos ni aprenden nuestros alumnos por el mero enseñar o aprender, sino como preparación para un ejercicio profesional competente.

Para aclarar mejor la dimensión práctica de nuestra docencia universitaria parece oportuno empezar por aclarar el concepto de profesión. En otro lugar he propuesto una definición tipológica de las profesiones en estos términos:

Profesiones son... aquellas actividades ocupacionales:

a) en las que de forma institucionalizada se presta un servicio específico a la sociedad,

b) por parte de un conjunto de personas (los profesionales) que se dedican a ellas de forma estable, obteniendo de ellas su medio de vida,

c) formando con los otros profesionales (colegas) un colectivo que obtiene o trata de obtener el control monopolístico sobre el ejercicio de la profesión,

d) y acceden a ella tras un largo proceso de capacitación teórica y práctica, de la cual depende la acreditación o licencia para ejercer dicha profesión. ${ }^{8}$

De los diferentes rasgos que caracterizan esta definición quisiera ahora centrarme en el que considero más nuclear, la razón de ser de lo que constituye cada profesión y que no es otra sino la búsqueda de esos fines o bienes con los que proporcionar un servicio específico profesionalizado. Los profesionales lo son por incorporarse al ejercicio de una práctica que busca alcanzar y proporcionar determinados bienes y servicios por los medios técnicos, con los conocimientos científicos disponibles, etc. El ejercicio profesional de la medicina lo que pretende es cuidar y restablecer la salud de las personas con arreglo a los saberes y técnicas disponibles en un momento histórico determinado. El fin del ejercicio profesional del juez es la

${ }^{8}$ A. Hortal (2005), Ética general de las profesiones, Bilbao, Desclée de Brouwer, (2a ed.), p. 51. 
administración de justicia conforme a las leyes; el fin del ejercicio profesional del abogado es el asesoramiento, defensa y representación de la persona de su cliente en relación con las leyes, los tribunales, la administración, etc.

A. Maclntyre distingue entre actividades y prácticas. Actividad sería cualquier cosa que hacen las personas buscando cualquier tipo de fin. Prácticas serían aquellas actividades cooperativas que persiguen lo que este autor llama "bienes intrínsecos". Bienes intrínsecos son aquellos que por estar constitutivamente ligados a una práctica sólo pueden conseguirse ejerciendo bien dicha práctica. Las profesiones son "prácticas" o pretenden hacer una aportación funcional específica a algún tipo de "prácticas", en el sentido que da a esta palabra A. Maclntyre. Y en la búsqueda incansable por mejorar las prestaciones profesionales ha resultado ser un elemento potenciador de las buenas prácticas profesionales la búsqueda de bases científicas para la propia actuación profesional. Ese fin práctico es el que ha hecho que las profesiones acudan a las universidades donde se investigan y se imparten los conocimientos que las profesiones necesitan para mejorar sus competencias.

Sobre el trasfondo de ese fin práctico de cada profesión es posible situar mejor la docencia de las disciplinas particulares que impartimos y darle un enfoque práctico a nuestro modo de enseñarlas. Para desentrañar lo que está en juego puede ayudarnos hacernos eco de los cinco rasgos con los que Asa Kasher caracteriza en un artículo reciente una práctica profesional. ${ }^{9}$ Dice este autor que una práctica puede considerarse profesionalizada si presenta los siguientes cinco elementos:

1. Un cuerpo sistemático de conocimientos relevantes [para saber cómo actuar en determinados asuntos en orden a obtener y proporcionar los bienes y servicios a los que se orienta constitutivamente la correspondiente profesión].

2. Una pericia o capacidad entrenada de solucionar problemas relevantes [en el mismo ámbito y con los mismos fines].

3. Una práctica de constante mejora o perfeccionamiento de los conocimientos y la pericia relevantes [compromiso profesional con la mejor manera de alcanzar esos fines].

4. Comprensión y capacidad de hacer comprender por qué hay que actuar de una o de otra manera en unos casos o en otros, incluyendo los casos extraordinarios poco comunes (comprensión "local").

${ }^{9}$ A. KASHER (2005), "Professional Ethics and Collective Professional Autonomy: A Conceptual Analysis", en: Ethical Perspectives: Journal of the European Ethics Network 11/1, 67-98. 
5. Comprensión "global" de la naturaleza del sistema de conocimiento y mejora.

Una práctica profesional ${ }^{10}$ puede pues definirse como un conjunto de actuaciones basadas en un cuerpo sistemático de conocimientos, habilidades y destrezas relevantes para resolver determinado tipo de problemas, y proporcionar determinados tipos de bienes o servicios. Una vez adquiridos y acreditados los conocimientos y destrezas básicos que son requisito indispensable para acceder al ejercicio profesional, cada profesional tiene el compromiso de renovarse, actualizarse y ampliar esos conocimientos, habilidades y destrezas. Mediante la dedicación asidua y prolongada a la práctica profesional está en condiciones de ir ampliando y consolidando esos conocimientos y destrezas que no sólo le capacitan para hacer las cosas como siempre se han hecho (casos ordinarios) sino para introducir innovaciones y mejoras en la obtención de los bienes y en la prestación de los servicios a los que se dedica su propia profesión.

Las profesiones se diferencian de los oficios porque los profesionales, se supone, no sólo saben hacer lo que se suele hacer y resolver los casos que suelen presentarse de forma más o menos frecuente o rutinaria, como por ejemplo, instalar o reparar una calefacción, manejar una grúa, arreglar un televisor, formatear un ordenador... El profesional añade a eso dos rasgos muy estrechamente relacionados: por una parte sabe por qué hay que actuar en este caso de esta manera y en el otro de otra, sabe explicar por qué una actuación es acertada y la otra no, y por eso mismo está en condiciones de abordar casos insólitos o especialmente difíciles. Esto descansa sobre la base de sus conocimientos no ocasionales, sino sistemáticos, y por otro en su compromiso de mejora y perfeccionamiento, de ampliación, actualización y afinamiento de los conocimientos adquiridos y de las nuevas pericias y técnicas disponibles que se van presentando a lo largo de su trayectoria profesional. El que de veras es buen profesional, no es meramente el que repite rutinariamente lo mismo que hizo una vez y que hace y sabe hacer cualquier profesional. El profesional por una parte tiene un compromiso de excelencia o de mejora continua y por eso mismo es quien está o debe estar en las mejores condiciones para enfrentarse con situaciones individuales, nuevas, tal vez inéditas o irrepetibles.

A los tres primeros rasgos anteriormente señalados añade Asa Kasher otros dos interesantes rasgos finales que completan su caracterización de lo que es una práctica profesional: la práctica profesional no termina de ser lo que es, si no es llevada a cabo en el marco de una comprensión de los criterios de excelencia acerca del

${ }^{10}$ A. KASHeR (2005), op. cit. 
bien interno de esa práctica profesional, y acerca de los conocimientos necesarios y los modos de actuar específicos de la misma. Eso es lo que Asa Kasher llama comprensión "local" de la propia práctica profesional. Un profesional es alguien que sabe de su propia práctica profesional, de su historia, de su sentido, de sus dificultades, de sus contextos, sabe dar razón de lo que hace y no sólo hacerlo.

Por último, esa comprensión no puede ser sólo "local", tiene que ser "global", lo que conlleva la capacidad de comprender esa práctica y los bienes y servicios que constitutivamente está orientada a obtener y proporcionar en un horizonte global de sentido acerca del significado de la correspondiente práctica para el conjunto de la vida humana de los individuos y de la sociedad. El buen profesional, el profesional culto y cultivado, no cae en lo que Ortega y Gasset llamaba "la barbarie del especialismo", sino sabe situar su dedicación profesional en el horizonte de comprensión de lo que es el conjunto de la vida humana y por eso mismo sabe situar su actividad profesional en el horizonte de su propia biografía. El que sólo es profesional, no es ni siquiera buen profesional, porque no acaba de entender que su profesión, la que sea, o es una contribución específica al conjunto de la vida humana o ha caído en la inhumanidad del profesionalismo que recorta lo humano.

Kasher identifica la ética profesional con la quinta característica. Yo la veo presente en los cinco niveles, o si se prefiere irradia desde el quinto a los cuatro anteriores en forma de obligación de saber y de saber hacer, de estar al día, actualizar y ampliar los conocimientos y destrezas inicialmente adquiridos, y de saber dar razón intelectual y socialmente de por qué hacemos lo que hacemos cuando actuamos profesionalmente.

Naturalmente, no todo lo mencionado se puede lograr en la etapa universitaria, ni todas las asignaturas que enseñamos aportan los mismo a su realización. Pero es necesario que la docencia y la vida universitaria siente las bases (los conocimientos teóricos y las habilidades y orientaciones prácticas) de lo que vaya a venir después, incentivar el interés por las metas a las que hay que orientar toda la adquisición de conocimientos y pericias y el mismo compromiso de mejora y perfeccionamiento. $\mathrm{Si}$ a eso se añade una comprensión "local" y "global" de un ejercicio profesional con el que es posible identificarse, entonces habremos enseñado con provecho, habremos hecho ver "para qué sirve" lo que enseñamos. 


\section{Dificultades, resistencias y ficciones}

No cualquier sentido práctico es válido, "útil" o provechoso para el fin que se pretende. En el último apartado trataremos de iluminar cómo la utilidad o provecho que nuestra formación académica trata de ofrecer a nuestros estudiantes tiene que contribuir a una sociedad más justa, a formar unas personas más cultas y formadas y -si es posible y lo aceptan- personas que a todo lo anterior unan el ser más y mejores creyentes. Ahora, en este apartado nos toca abordar con realismo las resistencias que el sentido práctico de nuestra enseñanza y de nuestra formación puede encontrar en nuestra manera de entender, enfocar y llevar a cabo nuestra docencia y la misma investigación.

Podríamos agruparlas en torno a tres núcleos (y un cuarto que añadiré, que diría el sabio bíblico) que pueden darse simultáneamente y potenciarse cada uno a los otros: el academicismo que de una u otra forma intenta proteger el propio ámbito frente a interferencias ajenas unas más legítimas que otras; la inercia, rutina o comodidad con la que uno se instala en el propio ámbito disciplinar, en sus conocimientos y métodos asentados, en los campos de investigación que viene cultivando y se desentiende de quienes desde fuera de ese ámbito formulan alguna alegación pertinente. Esto viene favorecido y a su vez favorece el aislamiento de las disciplinas académicas y la consiguiente dificultad para articular lo que dicen unas con lo que dicen otras, algo que la vida práctica requiere de modo imperativo. Estas dificultades llevan con frecuencia a que una cierta ficción o curriculum oculto (de estudiantes y profesores) se haga presente en el quehacer universitario, por la que no siempre coincide lo que las cosas son con lo que parecen ser, lo que se hace con lo que se dice.

Una primera fuente de dificultades radica en la distancia y la diferencia, no siempre bien percibida, no siempre bien formulada, entre la ciencia que se investiga, la ciencia que se enseña y la práctica profesional que se preparan para ejercer los estudiantes. La ciencia que se enseña se nutre de la investigación; pero no todo lo que se investiga se enseña; y la mayor parte de lo que enseña un profesor no lo ha investigado personalmente. Ahí puede haber una fuente de distorsiones al presentar con carácter pretendidamente científico lo que tal vez no son sino afirmaciones aprendidas y repetidas, pero tal vez necesitadas de revisión.

A esto viene a añadirse la amplitud con la que se maneja el concepto de ciencia que puede incluir materias y métodos tan dispares como la teoría de la evolución o el estudio de un determinado yacimiento paleoantropológico, la psicología conductista o la psicoterapia humanística, la teoría del estado, el derecho cons- 
titucional comparado o el derecho procesal, la fonética, la psicolingüística o las dificultades de aprendizaje, la macroeconomía, la contabilidad, la filosofía de la ciencia, la bioética o la filosofía del lenguaje, la historia social y política del renacimiento o la numismática, la cibernética o la resistencia de materiales... Creo que es bueno reconocer que no es ciencia en el mismo sentido y con las mismas garantías todo lo que pretende revestirse de su esplendor y prestigio. Es bueno que cada disciplina y cada profesor que la imparte conozca y transmita hasta qué punto puede reivindicar el carácter científico de las materias que enseña y sobre las que investiga. Y sería deseable que no se articule en términos científicos sino prácticos lo que es poner la ciencia al servicio de determinados fines perfectamente legítimos y socialmente necesarios aunque no sean estrictamente científicos. Sin embargo, seguimos hablando de ciencias del transporte o del deporte. Para relacionar correctamente la ciencia con la profesión conviene poner ciertos reparos a la tendencia a ver más ciencia de la que realmente hay en la vida académica, no digamos en las profesiones.

Como bien dice Ortega y Gasset en Misión de la universidad las profesiones, por ejemplo la medicina, no es una ciencia. La ciencia es problemática y crítica; se basa en lo que un autor llama el escepticismo organizado. En cambio la medicina y las profesiones en general utilizan para sus fines la base científica, pero están dispuestas a rellenar las lagunas de ignorancia con procedimientos aventurados que permitan salir del paso, llámese ojo clínico o arte de curar, procedimientos estandardizados, protocolos...

El profesor universitario puede encontrar en esa falta de cobertura científica una razón para alejarse de la práctica profesional; en alguna medida él tiene que marcar las distancias con los practicismos rutinarios que esconden muchas lagunas de conocimiento. Ésa es también hasta cierto punto su misión. Pero no puede encastillarse de tal manera en el academicismo que ignore la dimensión práctica de lo que enseña y la razón práctica de su contribución a la formación de profesionales.

Hoy no suele ser el problema que los profesores universitarios pretendan encerrarse en la torre de marfil, aislados del mundanal ruido. Ese pudo ser un problema de las universidades medievales que las universidades modernas, y los jesuitas con ellas, contribuyeron a superar. Pero sí es posible observar ciertos tics academicistas en los profesores universitarios. Al fin y al cabo nos dedicamos a enseñar e investigar en nuestro propio campo científico o disciplinar. Reivindicar enfáticamente el carácter estrictamente científico de lo que hacemos, enseñamos e investigamos en la universidad, puede ser también una forma de marcar distancias frente a 
la dimensión práctica de la vida profesional, mucho más prosaica y metida en lo incierto.

Esta distancia o alejamiento de la dimensión práctica reviste en ocasiones la forma de una descalificación de los intereses materiales o económicos que operan en la vida práctica y profesional, en contraste con el saber desinteresado del profesor universitario que supuestamente busca el saber por su propio valor intrínseco. Otra forma que reviste esta misma distancia es la valoración superior en el curriculum académico de la investigación en detrimento de la docencia. Nada hay que decir contra la investigación y sí mucho a favor de esta función universitaria sin la que la universidad degenera pronto incluso en la función docente. Pero sí puede ser una forma de postergar la formación práctica de los futuros profesionales, una función que si no es la más importante, sí es la mayoritaria en los momentos actuales y, desde luego, la que proporciona la principal fuente de ingresos de los centros universitarios no públicos en nuestro país.

Cabe además refugiarse en lo teórico y rehuir las complejidades de la práctica por razones menos nobles y confesables y por lo mismo más cuestionables: por seguridad, comodidad, rutina, inercia o pereza mental y a la vez por mantenerse en el territorio que uno domina sin aventurarse en terrenos complejos y sujetos a lo opinable y lo incierto.

Todas las profesiones, y en esto los docentes no somos ninguna excepción, tienden a sustituir el resultado final que busca proporcionar su actuación por la mera prestación profesional, sea cual sea el resultado. Los médicos no cobran por curar, sino por diagnosticar y poner un tratamiento, se cure o no se cure el enfermo. Los abogados no cobran por ganar los pleitos, sino por estudiarse los casos, asesorar y representar a los clientes ante los tribunales en los asuntos que ellos les encomiendan. En esa misma línea los profesores también tendemos a enseñar, aprendan o no aprendan los alumnos, les sirva o no les sirva lo que aprenden. En esa misma línea, repetir las afirmaciones científicamente contrastadas de la propia disciplina, desentendiéndose de si siguen siendo útiles, aplicables, suficientes para el ejercicio profesional en las condiciones actuales... puede ser una forma de no complicarse la vida. El positivismo dejó de ser intelectualmente plausible, pero es una forma cómoda de desentenderse de las complejidades de la vida práctica.

La vida tiene problemas; la universidad departamentos. Stephen Toulmin en un reciente libro ${ }^{11}$ invita a revisar el proceso por el que la racionalidad formal de las

$"$ St. Toulmin (2001), Regreso a la razón, Barcelona, Península. 
disciplinas académicas se ha ido alejando más y más de la experiencia y de la práctica. La creciente profesionalización de la vida académica ha llevado a una creciente especialización teórica y a la consolidación de disciplinas independientes, cada vez más aisladas de toda otra disciplina con la que no comparta supuestos, planteamientos y métodos; simultáneamente se han ido también aislando de todo contexto práctico. El excesivo hincapié en la pericia disciplinar es, en parte, producto de la burocratización del conocimiento en las instituciones académicas. ${ }^{12}$ Eso conlleva que en las actividades profesionales de disciplinas rígidamente estructuradas, se valora más la conformidad que la originalidad; o, más bien, la originalidad se tolera solo en la medida en que refuerza los valores esenciales de un departamento... el énfasis disciplinar en las tecnicidades de las ciencias humanas impone a los recién llegados una serie de anteojeras profesionales que dirigen su atención a ciertas consideraciones restringidamente definidas, impidiéndoles a menudo considerar su trabajo desde una amplia perspectiva humana. ${ }^{13}$

Toulmin concluye el capítulo dedicado a la proliferación y aislamiento de las disciplinas señalando que el problema no es tanto intelectual cuanto sociológico: Si al final del siglo XX las actividades profesionales han desarrollado un carácter extremadamente disciplinar, lo cual ha distorsionado sus logros, debemos tratar de comprender el origen de estos problemas. No es el enfoque intelectual de la disciplina lo que produce ese efecto; sino más bien el tipo de organización social en el que se lleva a cabo la tarea disciplinar. En una palabra, este, en el fondo, no es un fenómeno intelectual, sino sociológico. ${ }^{14}$

La ficción es probablemente la resultante acumulativa que amenaza con instalarse en una universidad que ha perdido el sentido social de lo que hace y que sólo se ve a sí misma por dentro y sigue haciendo lo que sabe hacer, despreocupándose de si es eso lo que hay que hacer, lo que se necesita en los tiempos que corren. Hay mucha ficción y mucha rutina en la universidad, también en la investigación ritualizada, no digamos en la enseñanza.

\footnotetext{
12 Ibid., p. 76.

${ }^{13}$ Ibid., p. 207.

14 Ibid., p. 227.
} 


\section{La dimensión práctica (utilitas) al servicio de las otras tres dimensiones}

Decíamos al comienzo que las cuatro dimensiones que proponen los centros universitarios de la Compañía de Jesús como caracterizadoras de su identidad y misión, tienen su pleno sentido cuando se las integra y no se las ve como separadas las unas de las otras. Esto vale para cada una de ellas, pero vale más si cabe, para la utilitas o dimensión práctica que sólo tiene sentido en relación a aquellos fines y bienes a los que sirve. Ser competentes, estar bien preparados, tener las habilidades y destrezas necesarias... todo eso está bien con tal de que esté al servicio de fines buenos. Ya nos hicimos eco de la afirmación de Santo Tomás que decía que lo útil toma su condición de bien de aquello para lo que es útil, para lo que sirve.

No nos toca aquí desarrollar en sus propios términos lo que se refiere a las otras dimensiones, pero sí explicitar lo que la utilitas puede contribuir a su realización así como la necesidad que tiene la dimensión práctica de conectar con esas otras dimensiones finalistas para que su aportación instrumental no quede truncada y carezca del sentido que se pretende darle.

No basta con ser competentes para ser justos, humanos o cristianos. Pero los profesionales que no son competentes no pueden ser ni justos ni humanos ni cristianos, al menos en su vida profesional. Veamos esto en las peculiaridades de cada dimensión a la que puede y debe servir la utilitas.

La capacidad práctica de realizar competentemente la propia actividad profesional proporciona efectividad y credibilidad al sentido social, humano y cristiano de los profesionales. Sólo haciendo las cosas con competencia puede haber justicia en la práctica profesional. Pero no basta con cada una por separado; hay que saber conectarlas. Cuando la capacidad práctica de realizar competentemente la propia actividad profesional va unida al compromiso social en favor de la justicia, este compromiso está en condiciones de hacerse efectivo al menos en los asuntos relacionados con la propia profesión. Cuando falta esa conjunción puede ocurrir que alguien trabaje por la justicia como voluntario en las horas libres, mientras pone su trabajo profesional al servicio de fines que poco o nada tienen que ver con la justicia. Como decía un compañero jesuita, hay gente que dedica cuatro horas semanales a trabajar con los marginados y el resto de la semana colabora con toda dedicación y competencia en actividades que generan marginación. Algo semejante cabría decir de una humanitas o de una fides "de tiempo libre" de quienes dejan la vida profesional a un lado cuando tratan de cultivar la propia humanidad o el compromiso cristiano. La mutua 
impregnación entre la competencia profesional y el sentido social, humano y cristiano debería favorecer que lo deseable sea factible y encuentre cauces de realización efectiva empezando por el lugar en el que uno trabaja más tiempo y con mayor preparación. De lo contrario ocurrirá lo que señala el aforismo de Nietzsche que hemos puesto delante de las líneas de este escrito: Quien no sabe encontrar el camino que conduce a su ideal lleva una vida más frívola y descarada que el hombre sin ideal.

La justicia tiene muchas facetas, pero una primera manera de relacionar las actuaciones justas de los profesionales con la competencia profesional es la de las prestaciones profesionales en sí mismas. Es de justicia que los destinatarios - clientes de los servicios profesionales reciban unas prestaciones profesionales competentes, que estén a la altura de lo que en cada profesión, en cada asunto y en cada momento cabe esperar de profesionales que se mantienen al día en los asuntos de su profesión. La incompetencia profesional, el cansancio, la burocratización y el sinsentido del propio trabajo profesional pueden hacer que se busque el sentido en contextos más amplios y gratificantes, pero ningún compromiso con la marginación o con la justicia global entre el Norte y el Sur dispensa de este deber de justicia que tiene todo profesional de ofrecer a quienes acuden a él o de la empresa u organismo para los que trabaja la prestación debida y competente. La torpeza y la chapuza conllevan ciertamente injusticia.

Más allá de las actuaciones profesionales puntuales, e incluyéndolas, hay una aportación profesional a la justicia que puede y debe hacerse desde la propia competencia profesional, entendiéndola ahora no sólo como habilidades y destrezas sino como lo que Asa Kasher llamaba comprensión "local" y comprensión "global". Un profesional no es sólo un técnico que pone sus destrezas al servicio de cualquier fin, es alguien que sabe lo que hace, lo que se trae entre manos, y está comprometido con las mejoras y con la máxima excelencia alcanzable en el ámbito de su práctica profesional. Sabe dar razón de por qué en éste o aquel caso es bueno actuar así o de la otra manera y, además de todo lo anterior, tiene una comprensión del significado social y humano de la propia profesión y de los bienes y servicios que esa profesión está orientada a proporcionar.

Por comprender el significado de su práctica profesional y del bien interno que proporciona para el conjunto de la vida humana, puede ayudar a que la concepción social de los bienes que proporciona su profesión sean comprendidos adecuadamente, algo básico para establecer los criterios y procedimientos adecuados para distribuirlos con justicia. No se distribuyen de la misma manera, ni por los mismos agentes, criterios y procedimientos las sentencias judiciales, los cargos públicos, los 
puestos de trabajo en las empresas privadas, las viviendas, la energía, los salarios, los beneficios empresariales, los cuidados sanitarios o la educación.

La sociedad civil está necesitada de una contribución competente y no corporativista por parte de los profesionales en torno a aquellos bienes con los que ellos están comprometidos y en los que son competentes. Esta responsabilidad social se ejerce a título personal o colectivamente y en cierta medida puede y debe iniciarse en la misma universidad.

La relación de la utilitas con la humanitas puede resultar más distante, pero no debiera ser así. Las humanidades han tenido tradicionalmente más que ver con el cultivo gratuito del ocio y las artes liberales que con el negocio y los oficios serviles que nos sitúan en el reino de la necesidad. Eso no tiene que seguir siendo así. Basta enunciarlo para suscitar visiones que se distancian de esta manera de ver. Tiene que ser posible humanizar la competencia y el mismo trabajo profesional. La cultura, el cultivo o formación humana de una personalidad rica y equilibrada no puede quedar fuera del tiempo de trabajo y del trabajo profesionalizado. Aunque eso se cuestiona en su formulación explícita suele ser algo que todos vivimos escindidamente en la vida real. De hecho quienes cultivan la dimensión estética, la literatura, o sencillamente las relaciones humanas suelen hacerlo fuera del ámbito laboral. El homo sapiens se ha convertido en homo faber, o, al menos, cuando es sapiens no es faber y cuando es faber no es sapiens. Tendría que ser posible atisbar la forma de cultivar el homo sapiens faber.

La integración de la utilitas con la humanitas en el ámbito profesional se traduce en una forma rica de identidad. La profesión es hoy una fuente primordial de identidad no sólo hacia fuera, sino también para la misma persona que la ejerce. Uno no sólo trabaja como ingeniero, sino que es ingeniero, o abogado, psicólogo o trabajador social. Es importante además que la competencia, dedicación y compromiso con la profesión no degenere en "barbarie del especialista" ni en la deshumanización de la propia vida del profesional. A ello ayuda y contribuye, por supuesto, también la comprensión global de la propia práctica profesional.

El sentido de todo lo que hacemos y conseguimos en el trabajo y en la familia, en el ocio y en el negocio, en la vida privada y en la pública se inscribe en el conjunto de un orden institucional y en el conjunto de la biografía completa de una vida que merezca la pena ser vivida y en la que tienen que tener un lugar el nacimiento, el crecimiento, el envejecimiento y la muerte, el trabajo, el descanso y la fiesta, la salud y la enfermedad, las capacidades y las carencias y la vulnerabilidad, la belleza y la eficacia, la comunicación y el silencio, la cooperación 
y el conflicto, la familia, los amigos y los otros, las instituciones, las empresas, la vida pública...

La humanitas alude a eso. Humano es el que sabe vivir y cultivar cada faceta humana dándole su importancia en el conjunto de una vida compuesta también por otras facetas con las que se integra en una cierta armonía vivible. Inhumano no es el que se sale de la piel de su especie, sino el que acentúa de tal manera que una faceta, cualquiera-por ejemplo la utilitas-anula o bloquea las demás.

Y por último la fides como perspectiva abierta, ofrecida, posible pero nunca impuesta, como una oferta de sentido dado y no sólo construido. Una fe que humaniza la eficacia y la eficiencia profesional. Una fe que se hace justicia desde la profesión... Es importante que dialoguemos, abundantemente en los centros universitarios de la Compañía de Jesús, sin censura de ningún signo, sobre las peculiaridades de esta cuarta dimensión (nunca mejor dicho). La fides se mueve en un nivel distinto de las otras tres. lustitia y humanitas tienen consistencia por sí mismas y dan consistencia a la utilitas que les aporta a su vez efectividad. La fides está en otro nivel y sólo se relaciona con la utilitas, a mi modo de ver, mediante la correspondiente integración personal y social de la utilitas con la iustitia y con la humanitas. 